\title{
Reconstruction of undergraduate analytical chemistry laboratory course
}

\author{
Rose Matilainen $^{1}$ (D) Anniina Koliseva ${ }^{1} \cdot$ Piia Valto $^{1} \cdot$ Jouni Välisaari $^{1}$
}

Published online: 19 October 2016

(C) Springer-Verlag Berlin Heidelberg 2016

\section{Introduction}

Traditionally, quantitative chemical analysis has been taught through a series of laboratory experiments utilizing different analysis methods. The student's role has been merely to measure and report the results [1]. In this traditional system, students do not learn to think independently and they do not get any sense of a real analysis process: definition of the goal, sampling, separation of the target analyte from sample matrix, measurement of the desired substance, evaluation and interpretation of the results, and reporting the results both in writing and orally [1-4]. They also get no sense of why one method is used instead of another, what are the strengths and weakness of the selected methods, and what is the connection to real-life applications $[2,5,6]$. Because the function of analytical chemistry and chemists is very important in decision making, concerning, e.g., medical, production, environmental, forensic, and foodstuff issues that are based on chemical analyses, it is paramount to include new ways to teach quantitative chemical analyses to increase students' interest in the subject. Although classic "wet chemistry" methods have given way to instrumental ones, they should still be included in basic analytical chemistry education as they are fundamental and absolute analytical methods [7]. Also, classic analytical techniques

Electronic supplementary material The online version of this article (doi:10.1007/s00216-016-9953-6) contains supplementary material, which is available to authorized users.

Rose Matilainen

rose.b.matilainen@jyu.fi

1 Department of Chemistry, University of Jyväskylä, Jyväskylä, Finland are indispensable in providing knowledge about how real samples should be treated before the measurement step, such as decomposition methods, separation techniques, preconcentration of analytes, etc. It is also important to understand that instrumental analyses provide only the final and usually the easier step in analytical processes [7].

The Analytical Chemistry Laboratory course in the Department of Chemistry at the University of Jyväskylä has been in the department's curriculum since the 1960s and only minor changes have been made to the experiments during the years. The course contained classic analytical methods such as gravimetry, different titration techniques, potentiometry, electroanalytical techniques, and spectrometric techniques, which were taught traditionally by doing short experiments. Students were allowed to do their analyses independently at any time when the laboratory was open. Instructions for the analyses were in the laboratory handout, which was followed like a cook-book, and the students completed the analyses almost without thinking about what one is doing and why. The samples that were analyzed were pure metal standards with known concentration. In an acceptable completion of the task, the result of the analysis should be within an error limit of $\pm 5 \%$ of the true value; if not, it must be redone. Typically, there were about 30 students in the laboratory doing their studies and they were guided by only one instructor. According to the students' feedback, this kind of a course was inhibiting, routinely completed, disconnected from reality, void of thinking and reasoning, and did not give a true perspective on real analytical processes. However, the students learned basic analytical methods and also how to report results.

According to the feedback given, we decided to reconstruct the course in 2014, both in terms of contents and pedagogy. Until today, the reconstructed course has been given twice, in the years 2014 and 2015. In literature, one can find many 
methods of implementations for laboratory courses in analytical chemistry, such as project-based learning $[1-6,8]$, themebased modular approach [9], and role-playing analytical chemistry laboratories $[10,11]$. In all these implementations, the aim is to increase students interest, independence, engagement, and critical-thinking skills, to use real-life applications to connect the analyses to the living environment, to introduce students to a real analytical process that also includes reporting the results both in writing and orally and to solve problems in small groups. The main purpose of the reform was to increase student-centered activity, cooperation, and inquiry-based learning. We also wanted to strengthen the connections to real-life, to develop students' critical-thinking skills, and to decrease the number of drop-outs during the course. In reconstructing the course, we considered all the above-mentioned approaches, and we concluded on the implementation described in this article. One of our goals was to use the contact teaching hours more efficiently for studentcentered learning compared with the traditional system where the instructor was like a duty officer. In this article, we also describe the timing of the new course and the feedback obtained from students and group instructors.

\section{Course structure}

The course is part of subject studies in chemistry, and typically participants are second year students. Usually there are 40 to 50 major students and about 20 minor students in the course. In the reconstructed model, students are divided into seven groups, with 8 to 10 students in each group. The group has one 4 h-laboratory session each week. Two groups work in adjacent laboratories at the same time. Each group has its own instructor for the entire period. Lecture courses Analytical Chemistry 1 (in period 1) and Analytical Chemistry 2 (in period 2) are arranged in parallel with the laboratory course. These lecture courses contain the theory of the methods used in the laboratory course; in the laboratory, students deepen their understanding between theory and practice. The timing of these courses is given in Table 1 .

The laboratory course contains traditional laboratory experiments used to develop basic laboratory skills, in which both classic and modern spectroscopy methods as well as the laboratory environment become familiar to students. In these experiments, students are allowed to bring their own samples when, e.g., tea, sea salt, table salt, mineral water, etc. are analyzed. The experiments are done within $10 \mathrm{wk}$, after which the last $3 \mathrm{wk}$ of the laboratory course are dedicated to a research project. In the research project, students may use the analytical methods learned in this laboratory course, but they may also use other methods found in literature that may be performed with the reagents and equipment available in the laboratory. The timing and laboratory experiments can be found in Table 2.

The research project goes on throughout the laboratory course. Each group has its own research problem given by the instructor and it is introduced in the first group meeting. The problems are not pre-examined, so the outcome is unknown beforehand to both the students and instructors. The five research projects chosen for the course are (1) analysis of elements in needles, (2) analysis of elements in water, (3) analysis of elements in soil, (4) quality assurance of inorganic fertilizer, and (5) quality assurance of dialysis solution. These research projects were selected to strengthen the real-life connections, to show the entire analysis process, and to allow students to use a wide variety of reagents and analytical methods. Two groups may have the same research project but they solve it independently. In the first group meeting, the instructor gives some literature material and tips for finding more material considering the problem. The group decides how to work in the laboratory to solve the given research problem. They should decide on sampling, sample preparation, elements to be measured, measurement methods to be used, the importance of analysis result, etc. The instructor gives only a list of elements from which three elements are selected for analysis. One element is analyzed with two different methods, one of which should not be an instrumental method. To keep the group on schedule, there are three separate group meetings with the instructor during the course, and each meeting has its own goal as shown in Table 2. Although the project period in the laboratory is short, the students have enough time for troubleshooting and even repeating the procedure. In this implementation, the instructor acts like an expert rather than a teacher. After the research project is concluded, the group analyzes the obtained results and seeks answers to important analytical questions: "Do different determination methods give similar results? Is the quality assurance of the sample what it should be (fertilizer, dialysis

Table 1 The timing of lectures and laboratory courses in analytical chemistry

\begin{tabular}{|c|c|c|c|c|c|}
\hline Time & Monday & Tuesday & Wednesday & Thursday & Friday \\
\hline $8-12$ & Lab group 1 & $\begin{array}{l}\text { Lecture course } \\
\quad(8-10)\end{array}$ & Lab groups 4,5 & $\begin{array}{l}\text { Lecture course } \\
\quad(8-10)\end{array}$ & $\begin{array}{l}\text { Lecture (problem solving) } \\
\quad(8-10)\end{array}$ \\
\hline $12-16$ & & Lab groups 2,3 & & Lab group 6 & Lab group 7 \\
\hline
\end{tabular}


solution)? Does traffic emission have an influence on elemental concentration of needles? Does the water sample fulfill the official criteria for drinking water, or soil sample the official criteria for cultivability?"

The laboratory course ends with a compulsory course seminar in a lecture hall in which each laboratory group gives a seminar presentation of its work and the obtained results. In the seminar, there is also an outside specialist in the field of analytical chemistry in the industry, who comments on each seminar presentation and asks questions. The specialist also gives his/her own presentation in which the meaning and importance of different analytical methods and obtained results in the industry field are pointed out. The role of the specialist is also to highlight the selected laboratory experiments' connections to working-life and to emphasize the accuracy and precision of analytical results.

\section{Research methods and data}

This research aims to show the outcome of the reconstruction of the Analytical Chemistry Laboratory course by evaluating students' and instructors' opinions about the reconstructed course and also by showing the importance of the connections of the course's laboratory experiments to real-life and the impact this has on the students' motivation and activity. The main research questions are:

1. How did the reconstruction of the course work in general?

1.1 How did the reconstruction affect the drop-out rate of the course?

1.2 How did the reconstruction affect the instruction of the course?

2. How did the students feel the reconstructed course?

2.1 How did the reconstructed model affect the students' motivation?

2.2 Did students see any connections between the course experiments and implementation, such as the research project and seminar day, and the reallife and working-life skills?

\section{Students' questionnaire}

Students' opinions, experiences, and impressions concerning the reconstructed course were obtained using a questionnaire (Electronic Supplementary Material, Appendix 1). The aim was to figure out the students' impressions of their motivation and activity, the realization of learning objects during the course, and their experience on research projects and group dynamics during the laboratory experiments. The questionnaire form included both Likert scale and open questions. Frequencies, averages, and standard deviations were calculated from the Likert scale questions. Open questions were analyzed qualitatively by using data-based qualitative content analysis.

Qualitative content analysis is used in qualitative descriptive studies. This method includes a systematic classification process of analyzed data, and the goal of the process is to identify repetitive themes or patterns in the research material [12]. In qualitative content analysis, the aim is to find the core meanings of the data, and to reduce the data to meaningful concepts. Also, the method can be defined suitable for subjective interpretation the data. In qualitative analysis, two researchers analyze the data independently, and the results are based on the consensus of the researchers. In data-based content analysis, the number of respondents' comments was calculated: thus the number of combined comments can be higher than the number of respondents.

The number of respondents was 45 in 2014 and 47 in 2015. In 2014, $38(84 \%)$ respondents were chemistry majors and 7 (16\%) were chemistry minors. In 2015, the numbers were 31 $(66 \%)$ and $16(34 \%)$, respectively.

\section{Interview study}

Instructors of the course in the years 2014 and 2015 were interviewed individually. We wanted to find out the instructors' opinions in relation to the role of instructor in the laboratory exercises, the activity of students, and the overall success of the reconstructed course. The used method was a semistructured theme interview. The research material was analyzed using data-based contents analysis. All eight instructors of the course were interviewed. The durations of the interviews varied between 19 and $39 \mathrm{~min}$.

\section{Results}

\section{Drop-out rate}

The need for the reconstruction of the Analytical Chemistry Laboratory course was also noticed by evaluating of the course drop-out rate. Previously, some of the students completed the course during many semesters or failed to complete the course at all. The yearly drop-out rate was between 50 and $70 \%$ before reconstructing of the course. After the reconstruction, the number of students dropping out has decreased in total from $53 \%$ (in the year 2012) to $6 \%$ (in the year 2015). The drop-out rate has also decreased almost $6 \%$ between the years 2014 and 2015 with the new course form. 
Table 2 The timing and laboratory experiments

\begin{tabular}{|c|c|c|}
\hline Week & Group experiment & Parallel group experiment \\
\hline 1 & $\begin{array}{l}\text { General subjects: laboratory experiments, } \\
\text { research project }\end{array}$ & $\begin{array}{l}\text { General subjects: laboratory experiments, } \\
\text { research project }\end{array}$ \\
\hline 2 & $\begin{array}{l}\text { Demonstration: "How to measure with } \\
\text { UV/Vis spectrophotometry?" }\end{array}$ & $\begin{array}{l}\text { Demonstration: "How to measure with } \\
\text { AAS spectrometry?" }\end{array}$ \\
\hline 3 & $\begin{array}{l}\text { Demonstration: "How to measure with } \\
\text { AAS spectrometry?" }\end{array}$ & $\begin{array}{l}\text { Demonstration: "How to measure with } \\
\text { UV/Vis spectrophotometry?" }\end{array}$ \\
\hline \multirow[t]{2}{*}{4} & $\begin{array}{l}\text { Titration of Fe with potassium permanganate } \\
\text { (sample: razor blade) } \\
\text { Research project (group): }\end{array}$ & $\begin{array}{l}\text { Titration of Fe with potassium permanganate } \\
\quad \text { (sample: razor blade) } \\
\text { Research project (group): }\end{array}$ \\
\hline & $\begin{array}{l}\text { Goals of the project and decision of the elements } \\
\text { to be analyzed }\end{array}$ & $\begin{array}{l}\text { Goals of the project and decision of the } \\
\text { elements to be analyzed }\end{array}$ \\
\hline 5 & $\begin{array}{l}\text { Determination of Fe by UV/Vis } \\
\text { (sample: razor blade) }\end{array}$ & $\begin{array}{l}\text { Determination of Fe by AAS } \\
\text { (sample: razor blade) }\end{array}$ \\
\hline \multirow[t]{2}{*}{6} & $\begin{array}{l}\text { Determination of Fe by AAS } \\
\text { (sample: razor blade) }\end{array}$ & $\begin{array}{l}\text { Determination of Fe by UV/Vis } \\
\text { (sample: razor blade) }\end{array}$ \\
\hline & Report of Fe analysis & Report of Fe analysis \\
\hline \multirow[t]{5}{*}{7} & $\begin{array}{l}-1 / 2 \text { group: acid-base titration } \\
\text { (result within error limit) }\end{array}$ & $\begin{array}{l}-1 / 2 \text { group: determination of } \mathrm{Na} \text { and } \mathrm{K} \\
\text { from mineral water by flame emission }\end{array}$ \\
\hline & $\begin{array}{l}-1 / 4 \text { group: determination of } \mathrm{F}^{-} \text {from tea } \\
\text { sample by ISE }\end{array}$ & $\begin{array}{l}-1 / 2 \text { group: determination of } \mathrm{Ni} \text { by } \\
\text { gravimetry }\end{array}$ \\
\hline & $-1 / 4$ group: determination of $\mathrm{Cl}^{-}$from sea salt by ISE & (result within error limit) \\
\hline & Research project (group): & Research project (group): \\
\hline & $\begin{array}{l}\text { Determination methods for selected elements and } \\
\text { timing }\end{array}$ & $\begin{array}{l}\text { Determination methods for selected } \\
\text { elements and timing }\end{array}$ \\
\hline \multirow[t]{3}{*}{8} & $-1 / 2$ group: acid-base titration & $\begin{array}{l}-1 / 2 \text { group: determination of } \mathrm{Na} \text { and } \mathrm{K} \text { from } \\
\text { mineral water by flame emission }\end{array}$ \\
\hline & $-1 / 4$ group: determination of $\mathrm{F}^{-}$from tea sample by ISE & $\begin{array}{l}-1 / 2 \text { group: determination of } \mathrm{Ni} \text { by } \\
\text { gravimetry }\end{array}$ \\
\hline & $-1 / 4$ group: determination of $\mathrm{Cl}^{-}$from sea salt by ISE & (result within error limit) \\
\hline \multirow[t]{4}{*}{9} & $-1 / 2$ group: determination of $\mathrm{Na}$ and $\mathrm{K}$ from mineral & $-1 / 2$ group: acid-base titration \\
\hline & water by flame emission & (result within error limit) \\
\hline & $\begin{array}{l}-1 / 2 \text { group: determination of } \mathrm{Ni} \text { by gravimetry } \\
\text { (result within error limit) }\end{array}$ & $\begin{array}{l}-1 / 4 \text { group: determination of } \mathrm{F}^{-} \text {from tea } \\
\text { sample by ISE }\end{array}$ \\
\hline & & $\begin{array}{l}-1 / 4 \text { group: determination of } \mathrm{Cl}^{-} \text {from sea } \\
\text { salt by ISE }\end{array}$ \\
\hline \multirow[t]{6}{*}{10} & $-1 / 2$ group: determination of $\mathrm{Na}$ and $\mathrm{K}$ from mineral & $-1 / 2$ group: acid-base titration \\
\hline & water by flame emission & (result within error limit) \\
\hline & $\begin{array}{l}-1 / 2 \text { group: determination of } \mathrm{Ni} \text { by gravimetry } \\
\text { (result within error limit) }\end{array}$ & $\begin{array}{l}-1 / 4 \text { group: determination of } \mathrm{F}^{-} \text {from tea } \\
\text { sample by ISE }\end{array}$ \\
\hline & & $\begin{array}{l}-1 / 4 \text { group: determination of } \mathrm{Cl}^{-} \text {from sea } \\
\text { salt by ISE }\end{array}$ \\
\hline & Research project (group): & Research project (group): \\
\hline & Complete analytical process & Complete analytical process \\
\hline $11-13$ & Research project & Research project \\
\hline 14 & Course seminar & Course seminar \\
\hline
\end{tabular}

\section{Students' questionnaire: Likert scale questions}

The course evaluation was performed by using Likert scale questions, and the percent values were calculated and compared between the years 2014 and 2015 (Table 3). Based on the questionnaire, in 2014 in total $96 \%$ of the students were satisfied with the course as a whole (agree and strongly agree); $76 \%$ reported that their interest in the subject increased during the laboratory course (av. 3.9), and $61 \%$ found analyzing their own samples meaningful (av. 4.0). The laboratory experiences and real-life connections clearly increased students' motivation, especially in the first year of the reconstructed course (see Table 3, Question "The connection between laboratory experiments and real-life improved my study motivation."). Over $80 \%$ of the students also found the course useful for their future studies (av. 4.2). 
Table 3 The answer distribution [\% of the Likert scale values, 2014/2015], averages and standard deviations (SD) (Likert scale) of the selected questions

\begin{tabular}{|c|c|c|c|c|c|c|c|}
\hline & \multicolumn{5}{|l|}{$\%$ 2014/2015 } & \multirow{2}{*}{$\begin{array}{l}2014 \\
n=45 \\
\text { Average (SD) }\end{array}$} & \multirow{2}{*}{$\begin{array}{l}2015 \\
\mathrm{n}=47 \\
\text { Average (SD) }\end{array}$} \\
\hline & Strongly disagree & Disagree & Neutral & Agree & Strongly agree & & \\
\hline $\begin{array}{l}\text { My interest in the subject increased during } \\
\text { laboratory course. }\end{array}$ & $0 / 0$ & $4 / 2$ & $20 / 24$ & $58 / 48$ & $18 / 26$ & $3.9(0.7)$ & $4.0(0.8)$ \\
\hline $\begin{array}{l}\text { I saw the connection between laboratory experiments } \\
\text { and real-life. }\end{array}$ & $0 / 4$ & $7 / 22$ & $20 / 35$ & $47 / 26$ & $27 / 13$ & $3.9(0.9)$ & $4.0(0.8)$ \\
\hline $\begin{array}{l}\text { The connection between laboratory experiments and } \\
\text { real-life improved my study motivation. }\end{array}$ & $0 / 4$ & $9 / 20$ & $27 / 33$ & $44 / 30$ & $20 / 13$ & $3.8(0.9)$ & $3.3(1.1)$ \\
\hline The analysis of own samples were meaningful. & $0 / 14$ & $2 / 3$ & $37 / 55$ & $20 / 17$ & $41 / 10$ & $4.0(0.9)$ & $3.1(1.1)$ \\
\hline The research project was successful in its entirety. & $0 / 0$ & $4 / 13$ & $22 / 19$ & $56 / 53$ & $18 / 15$ & $3.9(0.7)$ & $3.7(0.9)$ \\
\hline The seminar day was successful. & $0 / 0$ & $4 / 6$ & $7 / 13$ & $49 / 49$ & $40 / 32$ & $4.2(0.8)$ & $4.1(0.8)$ \\
\hline I got enough guidance for the research project. & $0 / 2$ & $9 / 15$ & $18 / 13$ & $42 / 47$ & $31 / 23$ & $4.0(0.9)$ & $3.7(1.1)$ \\
\hline $\begin{array}{l}\text { The course provided me with skills and knowledge that } \\
\text { will be useful in working- life. }\end{array}$ & $2 / 0$ & $2 / 0$ & $20 / 26$ & $40 / 49$ & $36 / 26$ & $4.0(0.9)$ & $4.0(0.7)$ \\
\hline I think the course will be useful in my future studies. & $2 / 0$ & $0 / 6$ & $16 / 6$ & $42 / 51$ & $40 / 36$ & $4.2(0.9)$ & $4.2(0.8)$ \\
\hline I'm satisfied with the course as a whole. & $0 / 0$ & $0 / 2$ & $4 / 11$ & $69 / 64$ & $27 / 23$ & $4.2(0.5)$ & $4.1(0.7)$ \\
\hline
\end{tabular}

In addition, the course seminar day was reported to be successful in both years by over $80 \%$ of the respondents. The research project and seminar day clearly increased students' motivation by enabling them to learn valuable working-life skills, such as problem solving, collaborating with other students, and scientific communication, as also reported before $[1,3]$.

The main difference between the years 2014 and 2015 was found to be the connection of the course samples and experiments to real-life. In the year 2014 , $74 \%$ of respondents agreed or strongly agreed on this connection, whereas it was $39 \%$ in the year 2015 (Table 3). This might be due to the fact that both own samples and real-life connections were emphasized more in the year 2014 when the reconstructed course was first presented. The difference between the years 2014 and 2015 can also been found in the averages of the questions "The analysis of own samples were meaningful" and "The connection between laboratory experiments and real-life improved my study motivation." The averages of answers to these questions decreased from 4.0 to 3.1 and from 3.8 to 3.3 , respectively.

\section{Students' questionnaire: open questions}

When opinions about the reconstructed course's laboratory experiments were queried, the research project, iron analysis with different methods, acid-base titration, and analyses of fluoride from a tea sample were considered the most memorable laboratory experiments as shown in Table 4. Students cited the research project as memorable or educational (11/52 comments, $21 \%$ ) because it allowed for independent planning, designing, and implementation of the research subject. The iron analysis was also cited as memorable (10/52 comments, $19 \%$ ) because it allowed the students to use and compare different methods. This actually also strengthens the fact that classic analytical methods (such as titration) are still important fundamental methods of analytical chemistry and they provide essential knowledge about real samples [7].

"Altogether it was sensible to do the analysis of elements on soil [research project]. You got to examine your own sample and working in a group was pleasant and at the same time educational." (Respondent No. 11/2014)
Table 4 The comparison of the comments between the years $2014(\mathrm{n}=52)$ and $2015(\mathrm{n}=54)$ in question 18 "Which one of the laboratory experiments do you remember especially well and why?"

\begin{tabular}{lll}
\hline & $2014(\%$ of all the comments) & 2015 (\% of all the comments) \\
\hline Research project & $11(21)$ & $14(26)$ \\
Fe analysis (Titration, UV/Vis, AAS) & $10(19)$ & $15(28)$ \\
Acid-base titration & $9(17)$ & $6(11)$ \\
$\mathrm{Ni}$ by gravimetry & $5(10)$ & $5(9)$ \\
$\mathrm{F}^{-} / \mathrm{Cl}^{-}$by ISE & $8(15)$ & $4(7)$ \\
Instrumental methods (AAS, UV/Vis) & $7(14)$ & $6(11)$ \\
General comments & $2(4)$ & $4(7)$ \\
\hline
\end{tabular}


"Determination of $F$ from tea sample, it is nice that samples have a close connection to real-life." (Respondent No. 7/2015)

"Determination of iron in many ways, because you got to use different equipment and compare various methods." (Respondent No. 43/2014)

"Determination of potassium and sodium, because it was closest to real-life and it was interesting to examine/handle a sample, which you had used earlier but never had thought about it from a chemical point of view." (Respondent No. 13/2014)

The main difference between the years 2014 and 2015 was in the use of ion selective electrode (ISE) when analyzing fluoride or chloride ions. In the year 2014, students were asked to bring their own samples, which clearly increased their interest in this measurement. Out of all the comments, only 4/52 (8\%) were negative and they covered mainly frustration in the titration technique or timing of the work (3/52). In the year 2015, 9/54 of the comments were negative, so the number increased from the previous year to some extent. Positive comments (in the year 2015) regarding acid-base titration (6/54) covered mainly the importance of understanding the connection between theory and practice.

Students' feedback concerning the research project (question 24 "How did you find the research project?") was mainly positive. In 2014, altogether 74 of the respondents' comments (74/90 comments, $82 \%$ ) were positive. Students found the research project, e.g., interesting or motivating (31/74) and educational (14/74). Also, students described how the research project helped them learn research skills: they found that their research skills, e.g., how to plan measurements, improved (10/74). In total 16 comments regarding the research projects were classified as negative $(16 / 90,18 \%)$. Students criticized the implementation of the course (12/16) and group dynamics in their groups (4/16).

"- The seminar brightened up the course." (Respondent No. 3/2014)

"Seminar work was a positive and mind-opening experience." (Respondent No. 37/2014)

"A 15 minute seminar presentation in a group of 10 people sounded like a catastrophe and unworkable, but in our group it worked well." (Respondent No. 14/2015)
In 2015,72 of the students' comments were positive (72/ 110 comments, $65 \%$ ). However, the number of negative feedback increased $(38 / 110,35 \%)$. Especially, guidance during the research project was evaluated as worse. Students criticized the organization and practical arrangement of research project (20/38) and working in their group (10/38). Also, they found the research project stressful or frustrating $(8 / 38)$.

The students also gave feedback and ideas on how this course could be further improved. Most of the comments were about the research project (21/47) and how its practical issues, such as workload, timing, and implementation, could be further improved (Table 5). Based on these suggestions, the course was further developed. The results show that in 2015 the negative comments about the research project and laboratory experiments decreased significantly.

\section{Instructors' interviews}

The instructors found the rearrangement of the course mainly positive and meaningful. They mentioned that teaching in the laboratory was much easier and more controlled, and according to one respondent, teaching was in general possible because the new setup removed overcrowding and queuing. The now clearly scheduled course simplified the preparations instructors needed to do for their teaching. In addition, group work method enabled effective teaching. Instructors reported that in the rearranged method they had time for high-quality learning discussions with students, and also students had time to process the contents of the topic. Indeed, the instructors did observe good peer interaction between students. However, one of the instructors considered the earlier arrangements more individual and thus better for students' learning.

Instructors found guiding during the research project challenging; especially in the beginning of their projects, students needed instructor's active participation in the developing process, and sometimes strict guidelines.

Interaction between students was active and partly educationally sterling. Instructors found that connections to real-life and analyzing their own samples motivated students. Also, students learned group working skills and thus acquired valuable abilities for working-life. Besides, the rearrangement of the course
Table 5 The comparison of the comments between the years $2014(\mathrm{n}=47)$ and $2015(\mathrm{n}=57)$ in question 48 "How can the course be further developed?"

\begin{tabular}{lll}
\hline & $\begin{array}{l}2014(\% \text { of all } \\
\text { the comments })\end{array}$ & $\begin{array}{l}2015(\% \text { of all } \\
\text { the comments })\end{array}$ \\
\hline Research project & $21(45)$ & $15(26)$ \\
Laboratory experiments & $11(23)$ & $4(7)$ \\
Pre-exercises & $2(4)$ & $3(5)$ \\
Seminar & $3(6)$ & - \\
General comments & $10(21)$ & $35(61)$ \\
$\quad$-Timing or workload & & $14(26)$ \\
\hline
\end{tabular}


motivated the less active students. According to the instructors, the aims of the course were achieved. All the respondents found the seminar day surprisingly positive. Especially, the participation of a professional from the chemical industry was mentioned as an idea that was successful.

\section{"It [Seminar day] was a positive surprise. I questioned the functionality of a group of 10 people. The perfor- mances were surprisingly good, consistent, and logical." (Instructor respondent No. 2) "It [Seminar day] was surprisingly good. Students knew their stuff and presented it well. The seminar day fit really well to the course and the outside specialist in the field of analytical chemistry from the industry was good." (Instructor respondent No. 8)}

Some of the instructors feared beforehand that the students' skills in analytical chemistry would decrease when the amount of experiments were reduced. After the course, most of the instructors commented that the rearrangement did not affect the students' analytical chemistry skills. However, the opinion of two instructors was adverse. Nevertheless, the instructors found that the increased use of analysis equipment brought the course closer to working-life.

\section{Conclusions}

The Analytical Chemistry Laboratory course was reconstructed because of the encountered problems regarding structure, timing, and contents of the traditional analytical laboratory course. The main purpose was to increase students' activity and motivation by means of meaningful laboratory experiments and increased connection of the course materials and experiments to real-life. In addition, students' critical-thinking skills were strengthened by pre-exercises and research project problems.

In order to achieve better learning results and higherquality discussions and to improve and develop group dynamics, the instructor worked with the same group throughout the course [13]. This way the instructor could leisurely focus on teaching one laboratory experiment at a time (compared with the old course structure) which also increased students' time to process each analytical phenomenon.

Students gave mainly positive feedback on the reformed course. Based on our research, the reconstructed Analytical Chemistry Laboratory course model increased students' motivation on general laboratory work and classic analytical chemistry methods. Over $96 \%$ of the students (in the year 2014) also valued the overall experience of the course. The increase of real-life connections and working-life skills (e.g., seminar day presentations, group work, and research planning skills) in the course also improved our students' motivation and efficiently decreased course drop-out rates. Studying in a familiar and safe group probably assists in completing the course. In addition, the seminar day was highly valued (over $80 \%$ ) as successful in both years studied. It was perceived that learning by doing a research project also requires new skills from the instructors. Thus, in the future, attention needs to be paid also to guidance and collaborative work of the instructors.

Acknowledgments The authors thank course instructors Lahtinen M., Laurila E., Lehtimäki E., Konu J., Rautiainen J., Tiihonen A., and Väisänen A. for their valuable work in the new course arrangement and suggestions for further improvement of the course. The authors also thank the students who participated in the laboratory courses in years 2014 and 2015 and gave valuable feedback of the course for further improvements.

\section{Compliance with ethical standards}

Conflict of interest The authors declare that they have no competing interests.

\section{References}

1. Bullen HA. Student-driven independent research projects: developing a framework for success in analytical chemistry. Anal Bioanal Chem. 2012. doi:10.1007/s00216-012-6153-x.

2. Arnold RJ. The water project: a multi-week laboratory project for undergraduate analytical chemistry. J Chem Educ. 2003;80:58-60.

3. Robinson JK. Project-based learning: improving student engagement and performance in the laboratory. Anal Bioanal Chem. 2013. doi:10.1007/s00216-012-6473-x.

4. Wenzel TJ. A new approach to undergraduate analytical chemistry. Anal Chem. 1995;67:470A-5.

5. Wenzel TJ. Does problem-based learning sacrifice content and fundamentals? Anal Chem. 1999;71:693A-5.

6. Wilson GS, Anderson MR, Lunte CE. Instrumental analysis at the University of Kansas: an experiment in problem-based learning. Anal Chem. 1999;71:677A-81.

7. Karayannis MI, Efstathiou CE. Significant steps in the evolution of analytical chemistry-Is the today's analytical chemistry only chemistry? Talanta. 2012. doi:10.1016/j.talanta.2012.06.003.

8. Amarasiriwardena D. Teaching analytical atomic spectroscopy advances in an environmental chemistry class using a project-based laboratory approach: investigation of lead and arsenic distributions in a lead arsenate contaminated apple orchard. Anal Bioanal Chem. 2007. doi:10.1007/s00216-007-1189-z.

9. Samide M, Akinbo O. Theme-based modular approach for delivering the undergraduate analytical chemistry curriculum. Anal Bioanal Chem. 2008. doi:10.1007/s00216-008-2240-4.

10. Walters JP. Role-playing analytical chemistry laboratories. Part 1: structural and pedagogical ideas. Anal Chem. 1991;63:977A-85.

11. Walters JP. Role-playing analytical chemistry laboratories. Part 3: experimental objectives and design. Anal Chem. 1991;63:1179A-91.

12. Patton MQ. Qualitative research and evaluation methods. 4th ed. Thousand Oaks: Sage; 2015.

13. Chin C. Teacher questioning in science classrooms: approaches that stimulate productive thinking. J Res Sci Teach. 2007. doi:10.1002 /tea.20171. 


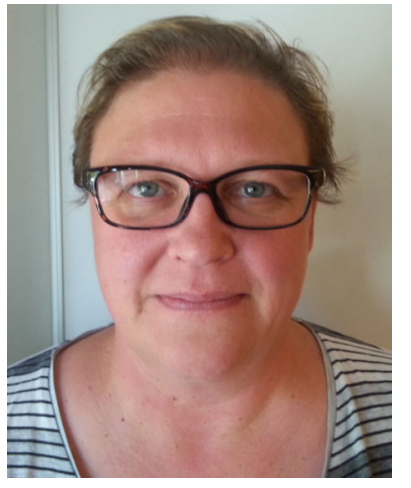

Rose Matilainen received her MSc in the year 1990 and $\mathrm{PhD}$ in the year 1997, both in Inorganic and Analytical Chemistry from University of Jyväskylä. She is currently working as a Senior Lecturer in Analytical Chemistry in the Department of Chemistry at the University of Jyväskylä. She is also ViceHead of the Department of Chemistry and is responsible for study affairs and study curriculum. Her research concentrates on development of analytical methods, especially in the field of spectroscopy and chromatography.

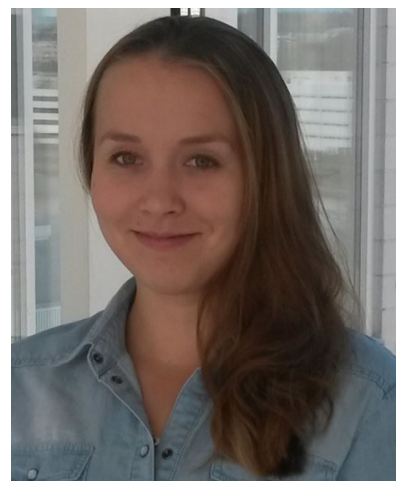

Anniina Koliseva received her MSc in Chemistry Teacher Education in the year 2014. She is currently working as a University teacher in the Department of Chemistry at the University of Jyväskylä. She teaches Chemistry Teacher Education courses. She also works as a coordinator of the Central Finland LUMA Centre, which is a part of the LUMA Centre Finland. The aim of LUMA Centre Finland is to inspire and motivate children and youth into mathematics, science, and technology through the latest methods and activities of science and technology education. The aim is also to support the life-long learning of teachers working on levels of education from early childhood to universities, and strengthen the development of research-based teaching.

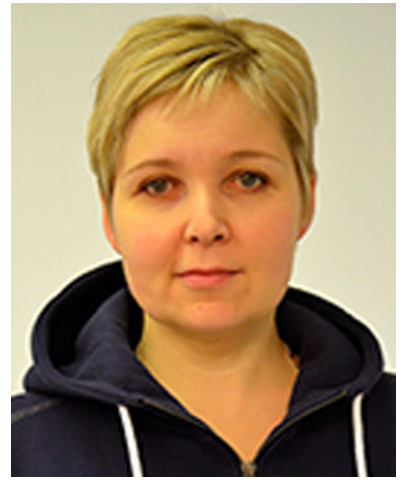

Piia Valto received her MSc in Organic Chemistry in the year 2000 and $\mathrm{PhD}$ in Applied Chemistry in the year 2011 from University of Jyväskylä, Finland. She is currently working as a University teacher in the Department of Chemistry at the University of Jyväskylä. She teaches analytical and organic chemistry laboratory courses and also works as a personal study advisor. The goal of her research is to increase chemistry students' study continuity, motivation, and well-being by developing Department of Chemistry's holistic study counselling and well-being model by focusing on Bachelor students' study counselling and first study year.

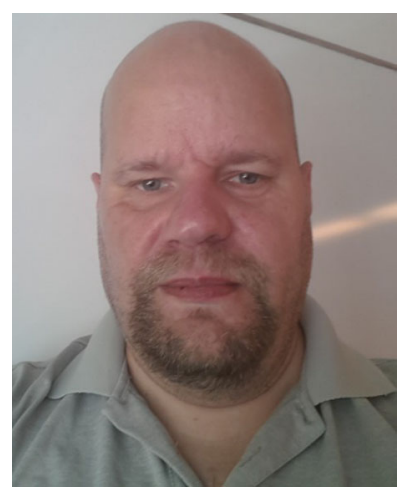

Jouni Välisaari received his MSc in the year 1992 and $\mathrm{PhD}$ in the year 1999, both in Inorganic and Analytical Chemistry, from University of Jyväskylä, Finland. $\mathrm{He}$ received MA (Educ.) in the year 2011 in Faculty of Education from University of Jyväskylä, Finland. He is currently working as a Lecturer in the Department of Chemistry at the University of Jyväskylä, Finland. His teaching and research interests are focused on Chemistry Education. 